Original Research Paper

\title{
The Time of Flooding Occurrence is Critical for Yield Production in Rice and Vary in a Genotype-Dependent Manner
}

\author{
${ }^{1}$ Jenjira Mongon, ${ }^{1}$ Arom Jantasorn, ${ }^{2}$ Prateep Oupkaew, ${ }^{3,4}$ Chanakan Prom-u-Thai, ${ }^{3,5^{*}}$ Hatem Rouached \\ ${ }^{1}$ Bodhivijjalaya College, Srinakharinwirot University, 10110 Bangkok, Thailand \\ ${ }^{2}$ Faculty of Agricultural Technology, Burapha University, 27160 Sakaew, Thailand \\ ${ }^{3}$ Agronomy Division, Department of Plant and Soil Sciences, \\ Faculty of Agriculture, Chiang Mai University, 50200 Chiang Mai, Thailand \\ ${ }^{4}$ Lanna Rice Research Center, Chiang Mai University, 50200 Chiang Mai, Thailand \\ ${ }^{5}$ Biochimie et Physiologie Moléculaire des Plantes Research Unit, Institut National de la Recherche Agronomique - \\ Centre National de la Recherche Scientifique - Montpellier University, Montpellier, France
}

Article history

Received: 12-05-2017

Revised: 19-05-2017

Accepted: 30-05-2017

Corresponding Author:

Hatem Rouached

Biochimie et Physiologie

Moléculaire des Plantes

Research Unit, Institut National de la Recherche Agronomique -

Centre National de la

Recherche Scientifique -

Montpellier University,

Montpellier, France

Email: hatem.rouached@inra.fr

\begin{abstract}
Flash floods occur in rainfed lowland and flood-prone areas and have a profound incidence on crop yield, which is tightly linked to worldwide food insecurity. The most flooding-threatened crop is rice. Under this condition, rice undergoes anoxic and post-anoxic shock that affects its growth, development capacity and ultimately causes an important grain yield loss. Therefore, the introduction of submergence-tolerant varieties in a flood-prone area was proposed as a preventive solution to limit these effects. Such a solution presents room for improvement and would benefit from a post-submergence management to ensure a better rice yield, yet remains to be defined. In this study, we assessed the effect of flooding on growth and yield of different rice varieties submerged at a different time of their developmental stage. We compared three rice varieties, namely Prachinburi 2 (PCR2), Kao Samer 1 (KSM1) and Neang Guang 5 (NG5), for their tolerance to 14 days of $50 \mathrm{~cm}$ depth submergence at 30,60 and 90 Days After Germination (DAG). At 30 DAG, the recovery ability of KSM1 was restricted, showing decreased shoot dry mass and grain yield, whereas photo assimilate transport of PCR2 and NG5 was altered, resulting in high leaf nitrogen $(\mathrm{N})$ concentration but low grain yield. Our data revealed that rice varieties were more tolerant to submergence at 60 and 90 DAG. In opposition to KSM1 and NG5 grain yield, PCR2 showed rapid recovery with a marked increase of shoot dry mass and grain yield. Taken together, our result indicates that de-submergence at late developmental stage promotes rice recovery and yield of tolerant variety. Gene discovery work is required to identify molecular players and pathways that are involved in submergence stress recovery in rice.
\end{abstract}

Keywords: Post-Submergence, Recovery Ability, Genotypic Variation, Rice

\section{Introduction}

Rice (Oryza sativa L.) is a staple food for half of world's population. One-third of rice-growing areas are rainfed and flood-prone area and at least 22 million hectares (ha) of them encounter to flooding stress (Ram et al., 2002; Ismail et al., 2012). The diffusion of gases in a flooded soil is reduced by $\sim 10^{4}$ times compared with non-flooded soil (Bailey-Serres et al., 2010). Consequently, limitation of available oxygen and carbon dioxide alters many vital cell functions, including aerobic respiration and photosynthesis (Bailey-Serres et al., 2012b). Rice plants suffer from anoxic during flooding and after flooding (post anoxic), which is marked by an increase of Reactive Oxygen Species (ROS) production (Ram et al., 2002; Ella et al., 
2003). Water depth that is generally observed in a floodaffected (rainfed) area vary from 30 to 50 centimeter (cm) (Ismail et al., 2012) and flood duration range from few days to more than two weeks (Ram et al., 2002; Ismail et al., 2012). Two typical kinds of water-flood can be distinguished. One is short duration over a few weeks and not very deep (flash flood) and the second is a deep flooding that lasts for a long time (Ito et al., 1999; Ram et al., 2002). Partial submergence of at least $50 \%$ of plant height was the most affected to reproductive stage, particularly disturbing the division of the pollen mother cells (Ito et al., 1999). It has been shown that rice grain yield decreased by $21 \%$ among six genotypes tested when water depth increased from 30 to $90 \mathrm{~cm}$ (Ito et al., 1999). Complete submergence that lasts longer than one to two weeks could cause severe injury in rice and eventually death (Ito et al., 1999). In the case of flash floods, the rapid increasing of water level caused of partial or complete submergence of rice (Ram et al., 2002). Flash floods can occur at any growth/development stages of rice from establishment to harvest and can causes a decrease of final yield by $10 \%$ or causes a complete loss (100\%) (Setter et al., 1997). Therefore, under unpredictable natural flood condition, using rice variety with adaption capacity may offer a solution to cope with this stress.

Recent studies have revealed the presence of an interaction between the mineral nutrients and oxygen to modulates rice growth capacity (Saenchai et al., 2016; Mongon et al., 2017). Availability of mineral nutrients for plants growth and development is important (Rouached et al., 2010; Bouain et al., 2014) to ensure a better growth and a high yield. Of these mineral nutrients, $\mathrm{N}$, phosphorus $(\mathrm{P})$ and potassium $(\mathrm{K})$ are known to plays important role in regulation of rice plants growth being involved in photosynthetic activity, a key process that drive high grain yield (Yoshida, 1981; Gautam et al., 2015). $\mathrm{N}$ is usually first added during rice cultivation and only then mixed-fertilizers N-P-K can be applied, approximately 20 days before heading to improve yield (Yoshida, 1981). In flash flood area, soil nutrients are dissolved and transported to the other floodplain surface, which leads to low nutrient soil (leaching) (Tsheboeng et al., 2014). Post-submergence nutrient application and particularly $\mathrm{N}$ was reported to improve the regain of chlorophyll and productivity in flood-prone area in tolerant cultivars (IR-64 Subl and Swarna Sub1) and susceptible cultivar (IR-20) (Lal, 2013; Gautam et al., 2014a; 2015). Therefore, N fertilizer is considered as a way to improve the photosynthesis and enhance grain yield after submergence in rice. This observation raised the question on whether this practice can be generalized on tolerant and non-tolerant rice cultivars? Is the application of N-P-K can enhance yield after submergence? And, finally, whether there are genetic basis for the yield that varies between rice cultivars? Further research is needed to answer these questions.

In this study, we examined the potential of three rice cultivars, namely Prachinburi 2 (PCR2), Kao Samer 1 (KSM1) and Neang Guang 5 (NG5), to recover from flooding at different growth stages followed by N-P-K fertilizers application. These three rice cultivars were chosen based on percentage of submergence survival screening in preliminary test in which PCR2 was the tolerant variety whereas KSM1 and NG5 was intolerant varieties. Our results demonstrated that the recovery from submergence stress varies depending on the rice developmental stage of the occurrence of this stress. The difference response to submergence observed between these rice varieties (genotypes) paves the way to a genetic investigation to discover genes involved in integrating nutrients homeostasis to post-emergences stress responses for agronomical and/biotechnological applications.

\section{Materials and Methods}

\section{Rice Varieties and Growth Conditions}

The experiment was carried out at Bodhivijjalaya College, Srinakharinwirot University, Nakhonnayok Province, Thailand during September 2015 - February 2016. Three rice varieties PCR2, KSM1 and NG5 were grown by direct seeded planting in the plastic pots $(30$ $\mathrm{cm}$ diameter and $40 \mathrm{~cm}$ height) containing $30 \mathrm{~cm}$ height of farms soil. Seven days old seedlings were thinned to three plants per pot. The water level was maintained at 5 $\mathrm{cm}$ from soil surface throughout the growth period. The 30, 60 or 90 Days After Germination (DAG), plants were transferred to the dark containers $(80 \mathrm{~cm}$ height $)$ containing full of tab water $(\mathrm{pH} \quad 7.3 \pm 0.04$ using pHTest30 model 35634-30, Singapore) to simulate flooding condition for 14 days and the control was nonflooding pots. Fertilizers were applied with recommended doses as broadcasting in two splits at 7-day-old (75 $\left.\mathrm{kg} \mathrm{N} \mathrm{ha}^{-1}\right)$ and again at $60 \mathrm{DAG}$ for nonflooded treatment or one day after de-submergence for flooding treatments $\left(75 \mathrm{~kg} \mathrm{~N} \mathrm{ha}{ }^{-1}, 50 \mathrm{~kg} \mathrm{P} \mathrm{ha}^{-1}\right.$ and $50 \mathrm{~kg} \mathrm{~K} \mathrm{ha}^{-1}$ ). Urea, triple superphosphate and potassium chloride fertilizer was used for $\mathrm{N}, \mathrm{P}$ and $\mathrm{K}$ source, respectively. The pots were arranged in a factorial randomized block design with four replications in the greenhouse. At ripening stage, approximately 120-dayold, aerial parts of three rice varieties were harvested. Plant height, plant biomass, nitrogen concentration in leaves, percentage of filled grain per panicle, 1000-grain weight, grain yield per hill were measured. The whole plant was collected and dried in an oven at $70^{\circ} \mathrm{C}$ for $72 \mathrm{~h}$ for dry mass measurement. Then, the leaves were separated for nitrogen concentration measurement by Kjeldahl method as described by Gautam et al. (2015). 


\section{Statistical Analysis}

ANOVAs on the data were performed using Statistix8 (analytical software, SXW, Tallahassee, FL, USA). Means were compared using LSDs at the $5 \%$ probability level and the means \pm standard error were calculated.

\section{Results}

Rice Genotypes and Growth Stage Determines the Recovery Capacity from Submergence Stress after Fertilization Application

It is well established that flooding differently affects rice shoot height and biomass (Ito et al., 1999; Gautam et al., 2014a; Anandan et al., 2015). In this study, we assessed these two parameters in three rice varieties, namely PCR2, KSM1 and NG5. These three rice varieties were submerged by water for 14 days to simulate flash flood either at 30, 60 or 90 DAG (30, 60 or 90 DAG). N-P-K fertilizers were applied one day after drainage. Compared to non-treated plants (Fig. 1a-c), PCR2, KSM1 and NG5 developed many nodal roots in submerged parts (Fig. 1d-1). Rice plants showed chlorosis symptoms in leaf sheath and leaf blade compared to non-flooded plants (Fig. 1). We next determined shoot dry weight and $\mathrm{N}$ concentration in these three rice varieties grown for 120 days. Our result show that all three varieties (PCR2, KSM1 and NG5) have a similar shoot height at 120 DAG regardless of the flooding time (30, 60 or 90 DAG; Fig. 2a). Measurements of shoot biomass (dry weight) reveal two different behaviors in the three tested rice varieties (Fig. 2b). On one hand, when flooding was applied at 30 DAG, the KSM1 variety exhibited significantly lower shoot dry biomass in comparison to KSM1 non stressed plants implying that its not able recover from flooding at this stage of growth (30 DAG). Nevertheless, when the stress was applied at 60 or 90 DAG, KSM1 showed a similar shoot dry biomass as control (KSM1 not stressed plants) suggesting that this rice variety could adapt to flooding at later stages (60 and $90 \mathrm{DAG}$ ) of growth, but not at 30 DAG. On another hand, shoot dry biomass of PCR2 or NG5 was not affected by flooding in early growth stage (30 DAG) in comparison to non-stressed control plants (Fig. 2b). Notably, at 60 and 90 DAG, PCR2 and NG5 recovered from flooding but also enhanced their growth. Our results showed that the shoot dry biomass of PCR2 and NG5 was significantly higher than PCR2 and NG5 not stressed plants (Fig. 3b). This result indicates that the effect of flooding stress is not only dependent on the rice genotype, but also depends on its developmental stage.

\section{Rice Genotype Influences the Nitrogen Accumulates after Submergence Episode}

It has been proposed that $\mathrm{N}$ application could improve rice growth in post-submergence stage (Lal,
2013; Gautam et al., 2014a; 2015). To assess to what extend this is valid and may vary in different rice genotypes. Therefore, we measured the $\mathrm{N}$ concentration in the leaves of three rice varieties PCR2, KSM1 and NG5 grown in the same growth conditions as described above. Our results showed that $\mathrm{N}$ concentration in leaves of KSM1 were significantly lower (decrease by $27.3 \%$ ) than control in 30, 60 or 90 DAG (Fig. 3c). Interestingly, both PCR2 and NG5 showed similar behavior and exhibited the highest $\mathrm{N}$ concentration in leaves at 30 DAG compared to non-flooded plants. Nevertheless, this difference was not observed at 60 and 90 DAG, as PCR2 and NG5 showed similar N concentration in leaves in comparison to non-flooded plants (Fig. 3c). Thus, there is no clear association between $\mathrm{N}$ accumulation in leaves after submergence and its shoot height and biomass production (Fig. 3); which reflects the capacity of each genotype to uptake and accumulates $\mathrm{N}$ after submergence episode.

\section{Grain yield Differs between PCR2, NG5 and KSM1 after Flooding and Fertilization Treatments}

Grain yield, grain per panicle and thousand-grains weight are affected by flooding stress. Here we assessed filled grain per panicle, thousand-grains weight and grain yield of PCR2, KSM1 and NG5 fertilized with N-P-K one day after drainage after being submerged by $50 \mathrm{~cm}$ water for 14 days for 30,60 or 90 DAG. Flooding at 30 DAG, the percentage of filled grain of PCR2 and NG5 was 25.2 and $23.7 \%$ decreasing, but not KSM1 that remains unchanged compared to non-flooded plants (Fig. 3a). At $60 \mathrm{DAG}$, flooding increases the percentage of filled grain of both varieties PCR2 and KSM1 for 23.3\% and $32.5 \%$, but NG5 variety remains unchanged compared to non-flooded plants (Fig. 3a). Interestingly, although flooding at 90 DAG causes a decrease of filled grain to the response observed in $60 \mathrm{DAG}$, they show different response compared with control. Indeed, PCR2, KSM1 and NG5 shows increase, unchanged, decrease of the percentage of filled grain compared to control, respectively (Fig. 3a). Further, we have determined the grain size of KSM1, NG5 and PCR2 after flooding followed. Flooding at 30 DAG decreased thousandgrains weight of all three rice varieties tested PCR2, KSM1 and NG5 compared to the same varieties grown under control condition (no stress) (Fig. 3b). The thousand-grains weight of KSM1 and NG5 was approximately $24.7 \%$ decreased regardless of developmental stages of flooding stress application, but with one fold more severe effects on KSM1 than NG5 (Fig. 3b). Flooding at 60 and 90 DAG did not change the thousand-grains weight of PCR2 compared to nonflooded plants (Fig. 3b). In term of grain yield, flooding at $30 \mathrm{DAG}$ has a severe effect on all tested rice varieties, PCR2, KSM1 and NG5 (Fig. 3c). Flooding treatment at 
either both at 60 or 90 DAG enhance grain yield of PCR2, which $74.8 \%$ higher compared to KSM1 and
NG5 and in turn showed high grain yield compared to control as well (Fig. 3c).

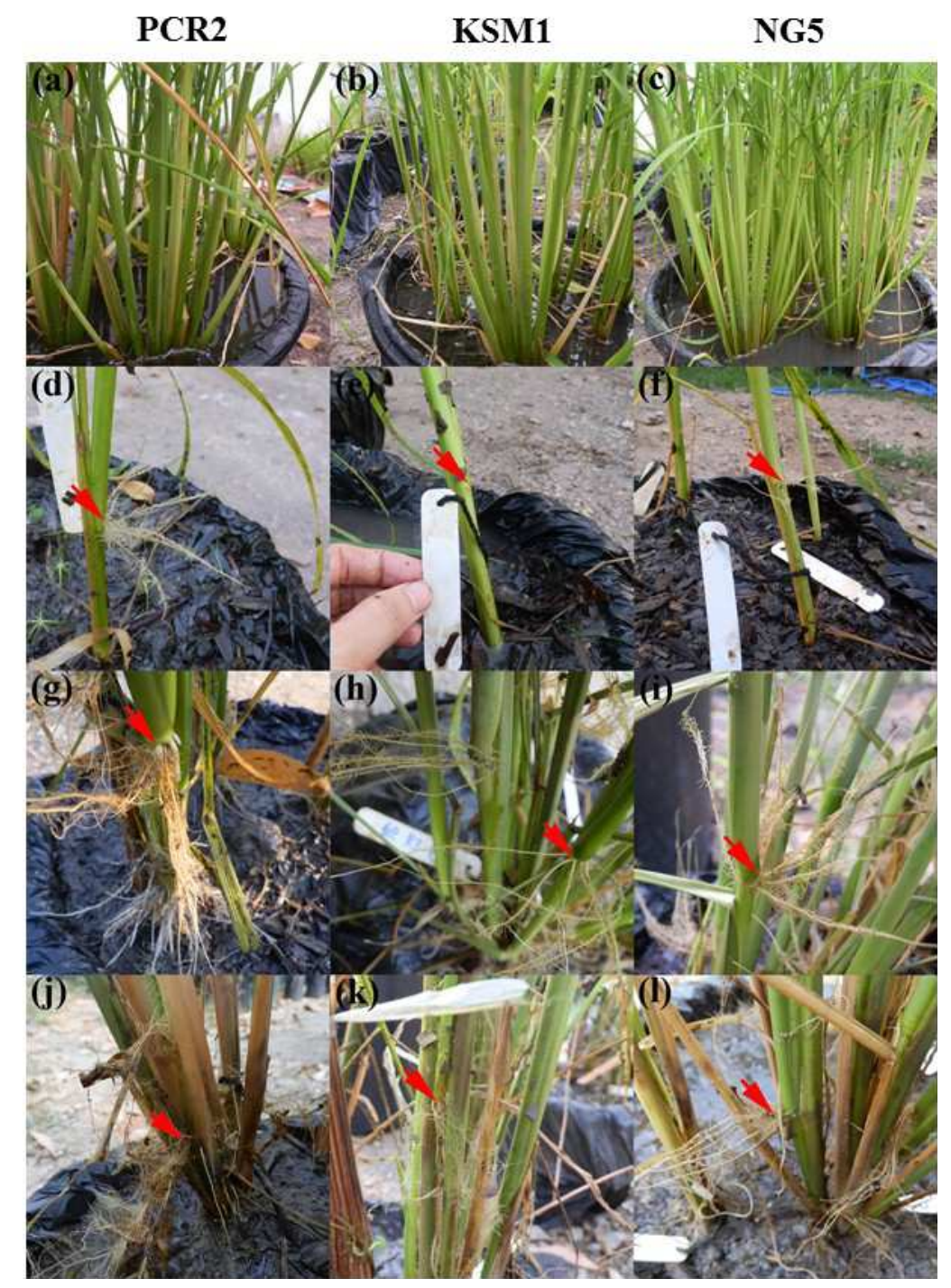

Fig. 1. Shoot phenotype of PCR2 (a, d, g and j), KSM1 (b, e, h and k) and NG5 (c, f, i and l) rice varieties growing in non-flooded condition (a-c), compared to 14 days of flooding in $50 \mathrm{~cm}$ depth at 30 Days After Germination (DAG) (d-f), 60 DAG (g-i) and 90 DAG (j-1). Arrows indicate nodal roots in flooded parts
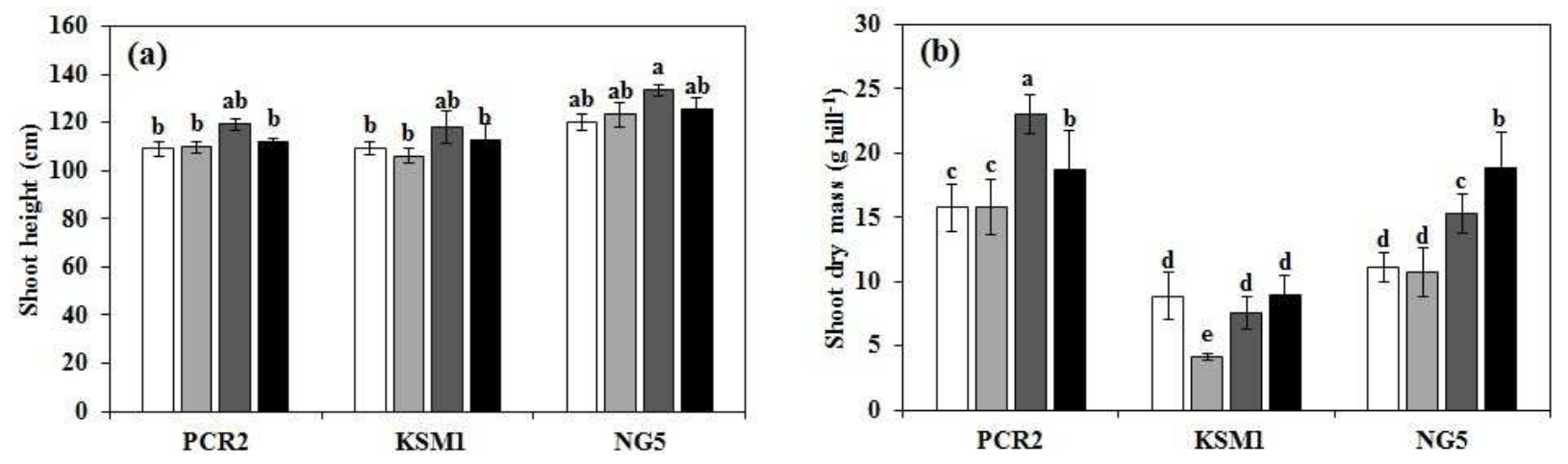


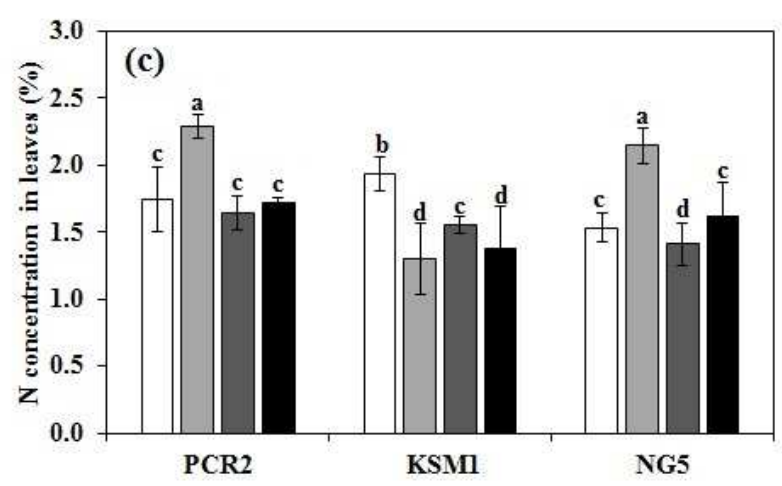

Fig. 2. Effect of post-flooding fertilizer application on shoot height (a), shoot dry mass (b) and $\mathrm{N}$ concentration in leaves (c) of PCR2, KSM1 and NG5 rice varieties. Flooding treatments were submerged with water for $50 \mathrm{~cm}$ from soil surface for 14 days at 30,60 or 90 Days After Germination (DAG) and water level of non-flooded condition was remained $5 \mathrm{~cm}$ from soil surface throughout the growing period. White bars represent non-flooded condition and light grey, dark grey and black bars represent flooding occurrence time at 30,60 and 90 DAG, respectively. Data are the means of four replicates \pm standard error. Mean with different letters were statistically difference at $\mathrm{p}<0.05$
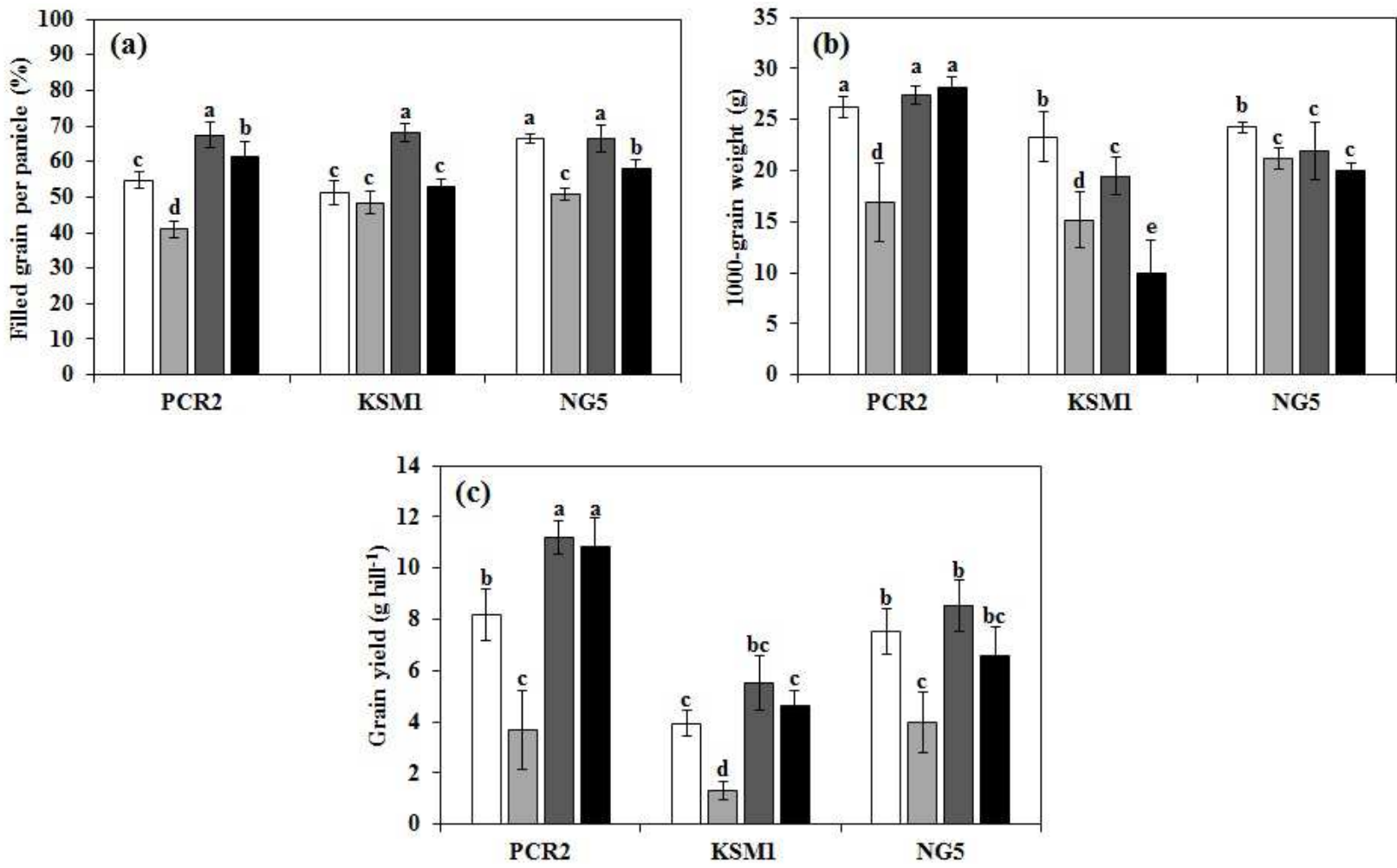

Fig. 3. Effect of post-flooding fertilizer application on filled grain per panicle (a), 1000-grain weight (b) and grain yield (c) of PCR2, KSM1 and NG5 rice varieties. Flooding treatments were submerged with water for $50 \mathrm{~cm}$ from soil surface for 14 day at 30 , 60 or 90 Days After Germination (DAG) and water level of non-flooded condition was remained $5 \mathrm{~cm}$ from soil surface throughout the growing period. White bars represent non-flooded condition and light grey, dark grey and black bars represent flooding occurrence time at 30,60 and 90 DAG, respectively. Data are the means of four replicates \pm standard error. Mean with different letters were statistically difference at $\mathrm{p}<0.05$

\section{Discussion}

Rice survival rate under water submergence varies between rice genotypes, plants development stage and time of stress application. Three rice varieties (PCR2, KSM1 and NG5) were considered in this study characterized with their differential tolerance capacity to submergence. Under deep flood condition $(50 \mathrm{~cm}$ of 
water from soil surface), while 30 DAG plants were completely submerged, the leaves and the panicles of 60 and 90 DAG plants were above water surface. It has been proposed that at early growth stage rice has high capability of internode elongation but can easily be injured by submergence stress because plant was succulent and having high non-structure carbohydrate (Bailey-Serres et al., 2010; Gautam et al., 2014b). In our study, the submergence of rice at 30 DAG resulted in more injury with less recovery capacity than submergence at 60 and $90 \mathrm{DAG}$, which manifests itself by the lowest grain yield. We observed that submergence at early growth stage (30 DAG) had no effect on shoot biomass of PCR2 and NG5, but caused a decrease of shoot biomass of KSM1 indicating that PCR2 and NG5 could recover from flooding stress but not KSM1. Our data further showed that flooding at early growth stage impacted the growth of intolerant rather than tolerant varieties. Flooding at early growth stage clearly resulted in decreased of grain yield of rice, which was not observed at tillering and reproductive stage.

It has been shown that at the reproductive stage, submergence could cause more damage in term of survival and productivity of rice as compared to active tillering and panicle initiation stage (Gautam et al., 2014b). Our results show that flooding at tillering stage (60 DAG) and reproductive stage (90 DAG) did not decreasing shoot biomass of three rice varieties. After floodwaters recedes, rice plants have to shift their metabolism from an anaerobic to an aerobic mode for acclimation to post-submergence condition (Ram et al., 2002; Ismail et al., 2012). The phenomenon of posthypoxic injury is probably brought about by generation of ROS (Ram et al., 2002; Ella et al., 2003). Postsubmergence $\mathrm{N}$ and $\mathrm{P}$ application maintained higher level of chlorophyll and conserved carbohydrate and increasing submergence tolerance (Gautam et al., 2014a; $2014 b$ ). This study confirmed that post-submergence fertilizer application (N, P and $\mathrm{K}$ ) help in increasing shoot growth and yield of tolerant rice variety (PCR2) and also stabilized shoot growth and yield of intolerant rice variety (KSM1). Moreover, fertilizer application seems to increase growth and stabilized yield of NG5, which was a moderate tolerant rice variety. $\mathrm{N}$ was found to improve the vigorous of rice plants for better tolerance to submergence at later growth stages (Gautam et al., $2014 \mathrm{~b}$ ). This responsiveness could be a result of 60 and 90 DAG plants had more shoot dry biomass than 30 DAG plants. Proper time of fertilizer application is a major agronomic practice promoting to the growth and yield of rice even under submergence. Post-submergence nutrient management could contribute substantially towards increasing productivity in flood-prone areas (Gautam et al., 2014a; 2014b; 2015). It has been shown that submergence tolerant genotypes had greater variance in partitioning of photo assimilate and carbohydrate for survival comparing to productivity (Anandan et al., 2015). This study revealed that applying $\mathrm{N}, \mathrm{P}$ and $\mathrm{K}$ fertilizer at 60 and 90 DAG increased grain yield of PCR2 and maintained grain yield of KSM1 and NG5, even though $\mathrm{N}$ concentration in their leaves was not markedly changing. Comparison to previous study that $\mathrm{N}$ and $\mathrm{P}$ application after submergence increased leaf $\mathrm{N}$ concentration and yield of IR-20, IR-64 Sub1 and Swarna Sub1 varieties (Gautam et al., 2015). However, earlier studies reported that at the end of recovering period, the difference in leaf $\mathrm{N}$ concentration among plants from three flooding depth treatment was small, indicating photosynthetic products in leaves may have been transported to the other parts for recovery (Miao and Zou, 2012; Chen et al., 2013). Applying fertilizer at late growth stage could improve grain yield of submerged rice possibly due to the ability of translocation of photosynthetic products from leaves to different parts for plants to recover (Gautam et al., 2015). In opposition, at 30 DAG the N concentration in leaves of PCR2 and NG5 was highest but grain yield was drastically low suggesting that leaf photosynthate transport could be restricted.

An adaptive feature of rice to submergence condition is the internode elongation. It is believed that rice plants have to maintain their foliage above the water surface to perform respiration and photosynthesis (Hattori et al., 2011; Ismail et al., 2012). Nevertheless, the high submergence tolerant cultivar, FR13A, has low capacity of internode elongation, but it could survive underwater for over 2 weeks (Ram et al., 2002; Bailey-Serres et al., 2010). Furthermore, 69 cultivars known with their vigorous elongation had a poor submergence tolerance (Ram et al., 2002). Our data showed that PCR2, KSM1 and NG5 had no strongly increase their shoot height whilst submerging. At $30 \mathrm{DAG}$, shoot dry mass of KSM1 was decreasing but not those of PCR2 and NG5 (Fig. 2b). At 60 and 90 DAG, while shoot dry mass of KSM1 remained stable, those of PCR2 and NG5 were increased. These results revealed that KSM1 is the intolerant variety and the most sensitive stage was early growth stage. Thus, submergence tolerance of rice may not be only correlated with internode elongation but also capable of plant recovery as shown by the increase of shoot dry mass of PCR2 and NG5. Another characteristic of rice submergence tolerance was the ability to maintain high non-structural carbohydrate reserves in shoots (Ismail et al., 2013) and rapid recovery of tillers and leaf area production that were ensured high yield (Singh et al., 2009). We observed an increase of dry biomass of PRC2 at 60 and 90 DAG in comparison with nonflooded plants. This indicates the potential of PCR2, which was not only to cope with flooding stress but also to adapt itself to overcome the stress.

All in all, this study clearly showed that the most susceptible growth stage of rice to flash flood was early growth stage. The important characteristic of the tolerant 
variety was rapid recovery and well response to $\mathrm{N}, \mathrm{P}$ and $\mathrm{K}$ fertilizer application. Therefore, using a tolerant variety integrated with post-submergence nutrient management may help farmers to encounter the problem of flood-prone lowland area and secure higher yield. Variation in submergence tolerance was observed between different rice genotypes, which indicates the existence of genes and molecular pathways that underline this differential capacity to tolerate such stress. To cite only few, earlier genetic research effort lead to the identification of a major Quantitative Trait Locus (QTL), SUB1, associated with submergence tolerance, used to bred into popular rainfed lowland rice varieties sensitive of complete submergence (Singh et al., 2009; Bailey-Serres et al., 2012a). Therefore, further genetic work has to be undertaken using rice varieties with contrasting behavior under flooding, such as the varieties identified in this study and other documented in literature, to identify additional key genes that regulate the rice yield under flash flooding.

\section{Acknowledgement}

This work was supported by Srinakharinwirot University - Thailand (grant no. 753/2558) to JM.

\section{Author's Contributions}

Jenjira Mongon: Designed the research, performed the experiment and analyzed the data and wrote the manuscript.

Arom Jantasorn, Prateep Oupkaew and Chanakan Prom-u-Thai: Performed the experiment and analyzed the data.

Hatem Rouached: Supervised this project, wrote the manuscript and final approved the manuscript

\section{Ethics}

The authors declare no conflict of interest.

\section{References}

Anandan, A., S. Kumar Pradhan, S. Kumar Das, L. Behera and G. Sangeetha, 2015. Differential responses of rice genotypes and physiological mechanism under prolonged deepwater flooding. Field Crops Res., 172: 153-163. DOI: $10.1016 /$ j.fcr.2014.11.007

Bailey-Serres, J., T. Fukao, P. Ronald, A. Ismail and S. Heuer et al., 2010. Submergence tolerant rice: SUB1's journey from landrace to modern cultivar. Rice, 3: 138-147. DOI: 10.1007/s12284-010-9048-5

Bailey-Serres, J., T. Fukao, D.J. Gibbs, M.J. Holdsworth and S.C. Lee et al., 2012a. Making sense of low oxygen sensing. Trends Plant Sci., 17: 129-138. DOI: $10.1016 / \mathrm{j}$.tplants.2011.12.004
Bailey-Serres, J., S.C. Lee and E. Brinton, 2012b. Waterproofing crops: Effective flooding survival strategies. Plant Physiol., 160: 1698-1709. DOI: $10.1104 /$ pp.112.208173

Bouain, N., M. Kisko, A. Rouached, M. Dauzat and B. Lacombe et al., 2014. Phosphate/zinc interaction analysis in two lettuce varieties reveals contrasting effects on biomass, photosynthesis and dynamics of $\mathrm{Pi}$ transport. BioMed Res. Int., 2014: 548254-548252.

DOI: $10.1155 / 2014 / 548254$

Chen, H., M.F. Zamorano and D. Ivanoff, 2013. Effect of deep flooding on nutrients and non-structural carbohydrates of mature Typha domingensis and its post-flooding recovery. Ecol. Eng., 53: 267-274. DOI: 10.1016/j.ecoleng.2012.12.056

Ella, E., N. Kawano, Y. Yamaushi, K. Tanaka and A.M. Ismail, 2003. Blocking ethylene perception enhances flooding tolerance in rice seedlings. Funct. Plant Biol., 30: 813-819. DOI: 10.1071/FP03049

Gautam, P., B. Lal, R. Raja, M.J. Baig and D. Haldar et al., 2014a. Post-flood nitrogen and basal phosphorus management affects survival, metabolic changes and anti-oxidant enzyme activities of submerged rice (Oryza sativa). Funct. Plant Biol., 41: 1284-1294. DOI: $10.1071 / \mathrm{FP} 14093$

Gautam, P., B. Lal, R. Raja, R. Tripathi and M. Shahid et al., 2015. Effect of simulated flash flooding on rice and its recovery after flooding with nutrient management strategies. Ecol. Eng., 77: 250-256. DOI: 10.1016/j.ecoleng.2015.01.033

Gautam, P., A.K. Nayak, B. Lal, P. Bhattacharyya and R. Tripathi et al., 2014b. Submergence tolerance in relation to application time of nitrogen and phosphorus in rice (Oryza sativa L.). Environ. Exp. Bot., 99: 159-166.

DOI: $10.1016 /$ j.envexpbot.2013.11.012

Hattori, Y., K. Nagai and M. Ashikari, 2011. Rice growth adapting to deepwater. Curr. Opin. Plant Biol., 14: 100-105. DOI: 10.1016/j.pbi.2010.09.008

Ismail, A.M., D.E. Johnson, E.S. Ella, G.V. Vergara and A.M. Baltazar, 2012. Adaptation to flooding during emergence and seedling growth in rice and weeds and implications for crop establishment. AoB Plants, 2012: pls019-pls019. DOI: $10.1093 /$ aobpla/pls019

Ismail, A.M., U.S. Singh, S. Singh, M.H. Dar and D.J. Mackill, 2013. The contribution of submergence-tolerant (Sub1) rice varieties to food security in flood-prone rainfed lowland areas in Asia. Field Crops Res., 152: 83-93. DOI: $10.1016 /$ j.fcr.2013.01.007

Ito, O., E. Ella and N. Kawano, 1999. Physiological basis of submergence tolerance in rainfed lowland rice ecosystem. Field Crops Res., 64: 75-90. DOI: $10.1016 / \mathrm{S} 0378-4290(99) 00052-0$ 
Lal, R., 2013. Climate-strategic agriculture and the water-soil-waste nexus. J. Plant Nutr. Soil Sci., 176: 479-493. DOI: 10.1002/jpln.201300189

Miao, S.L. and C.B. Zou, 2012. Effects of inundation on growth and nutrient allocation of six major macrophytes in the Florida Everglades. Ecol. Eng., 42: 10-18.

DOI: $10.1016 /$ j.ecoleng.2012.01.009

Mongon, J., N. Chaiwong, N. Bouain, C. Prom-u-Thai, D. Secco et al., 2017. Phosphorus and iron deficiencies influences rice shoot growth in an oxygen dependent manner: Insight from upland and lowland rice. Int. J. Mol. Sci., 18: 607-607. DOI: $10.3390 /$ ijms 18030607

Ram, P.C., B.B. Singh, A.K. Singh, P. Ram and P.N. Singh et al., 2002. Submergence tolerance in rainfed lowland rice: Physiological basis and prospects for cultivar improvement through markeraided breeding. Field Crops Res., 76: 131-152. DOI: $10.1016 / \mathrm{S} 0378-4290(02) 00035-7$

Rouached, H., D. Secco and B.A. Arpat, 2010. Regulation of ion homeostasis in plants: Current approaches and future challenges. Plant Signal. Behav., 5: 501-502. DOI: 10.4161/psb.11027
Saenchai, C., N. Bouain, M. Kisko, C. Prom-u-Thai and P. Doumas et al., 2016. The involvement of OsPHO1;1 in the regulation of iron transport through integration of phosphate and zinc deficiency signaling. Front. Plant Sci., 7: 396-396. DOI: $10.3389 /$ fpls.2016.00396

Setter, T.L., M. Ellis, E.V. Laureles, E.S. Ella and D. Senadhira et al., 1997. Physiology and genetics of submergence tolerance in rice. Ann. Bot., 79: 6777. DOI: 10.1093/oxfordjournals.aob.a010308

Singh, S., D.J. Mackill and A.M. Ismail, 2009. Responses of $S U B 1$ rice introgression lines to submergence in the field: yield and grain quality. Field Crops Res., 113: 12-23. DOI: 10.1016/j.fcr.2009.04.003

Tsheboeng, G., M. Bonyongo and M. Murray-Hudson, 2014. Flood variation and soil nutrient content in floodplain vegetation communities in the Okavango Delta. S. Afr. J. Sci., 110: 1-5.

DOI: $10.1590 /$ sajs.2014/20130168

Yoshida, S., 1981. Fundamentals of Rice Crop Science. 1 st Edn., Int. Rice Res. Inst., Manila, ISBN-10: 9711040522 , pp; 269. 